\title{
FOREIGN BODY OESOPHAGUS IN AN INFANT: A RARE CASE
}

Faiz muqtadir ${ }^{1}$, M. Muniraju², Khalid Gufran ${ }^{3}$

\section{HOW TO CITE THIS ARTICLE:}

Faiz muqtadir, M. Muniraju, Khalid Gufran. "Foreign Body Oesophagus in an Infant: A Rare Case". Journal of Evolution of Medical and Dental Sciences 2015; Vol. 4, Issue 19, March 05; Page: 3371-3374,

DOI: $10.14260 /$ jemds/2015/484

ABSTRACT: Foreign body ingestion is a potentially serious problem that is observed mainly in children aged six months to three years. Children who have swallowed foreign bodies are asymptomatic most of the time; hence doctors must maintain a high index of suspicion.

KEYWORDS: foreign body, infant, esophagoscopy, stridor.

INTRODUCTION: Ingestion of foreign body in pediatric population is a common but serious incident. Curiosity and preference to oral exploration are the two key factors in its prevalence.

Children of the age 5 months - 8 years are the highest risk for foreign body ingestion.(1) In neonates such an occurrence is rare ${ }^{(2-4)}$ and may pose a difficult management problem for the surgeons. The successful location and extraction of this foreign body demands substantial patience, skills and multidisciplinary team approach. This paper primarily focuses on the management problems encountered and various options available; in particular use of pediatric bronchoscope with optical forceps for retrieving ingested foreign bodies in neonates.

CASE REPORT: A 9 month old male baby was admitted, with history of accidental ingestion of a piece of jewelry, followed by irritability and refusal to feed. (Figure no. 1).

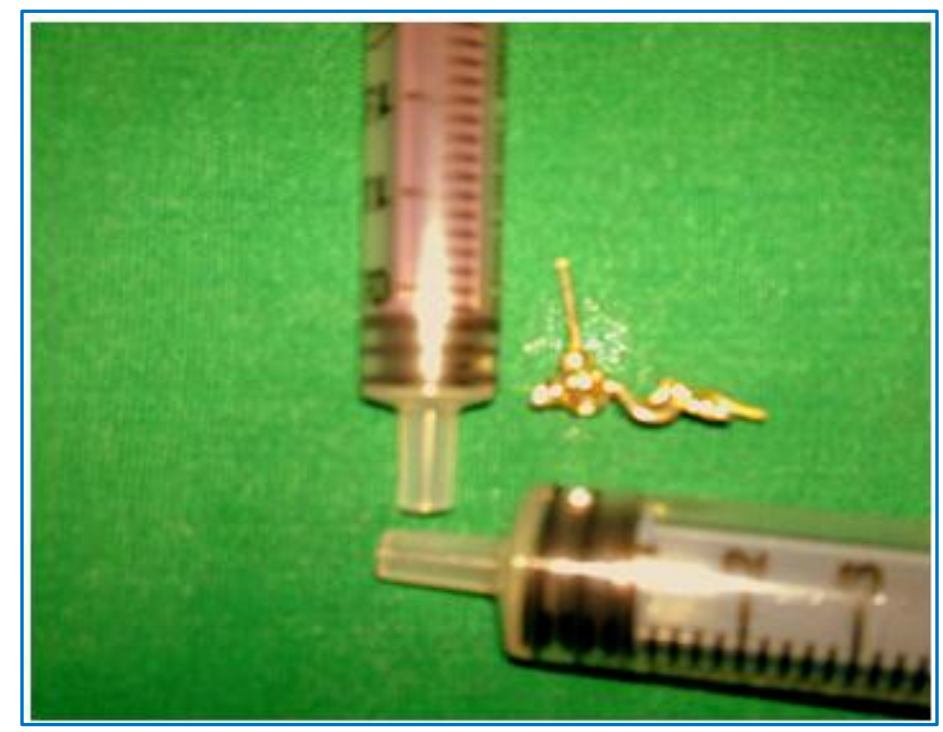

Fig. 1 


\section{CASE REPORT}

FIGURE 2: Plain x-ray revealed an impacted ear ring in the upper part of esophagus (Figure 2).

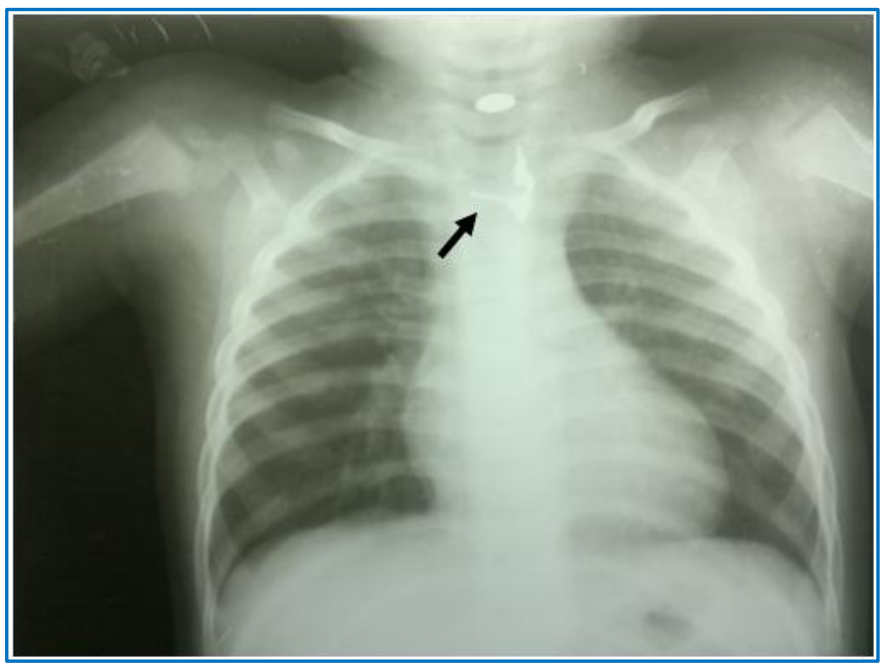

Fig. 2

The foreign body was removed successfully under general anesthesia by using pediatric bronchoscopic sheath (3.5' $26 \mathrm{~cm}$, Storz) with fiberoptic rigid grasping forceps $(35 \mathrm{~cm}$, Storz). (Figure no. 3).

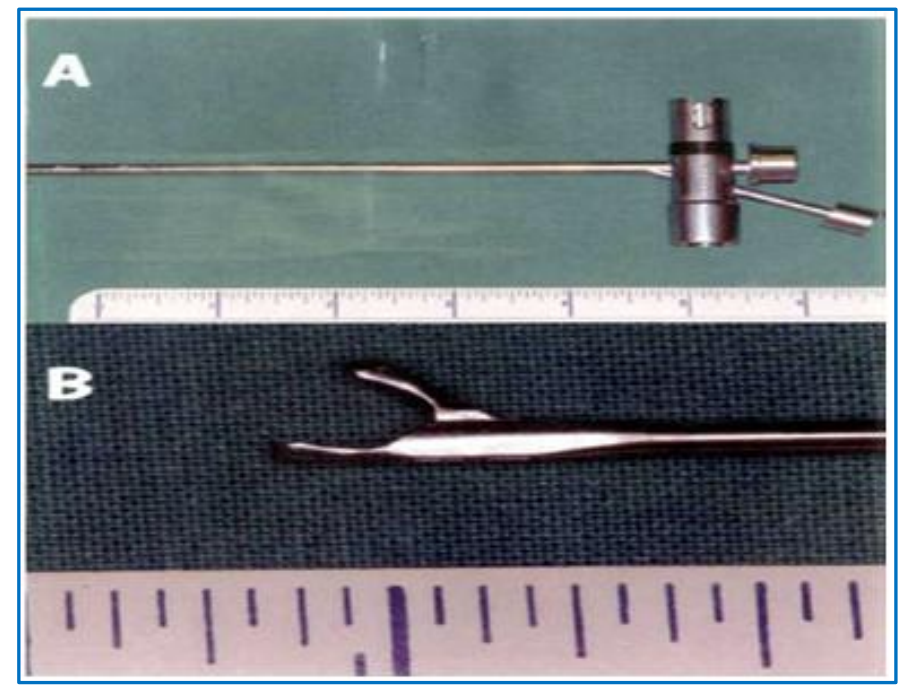

Fig. 3

One of the most serious causes of morbidity and mortality in children below 5 years of age are swallowed and inhaled foreign bodies; children of age 5 month - 8 years are at the highest risk of foreign body ingestion.(1) However, the incidence of esophageal foreign body in neonate is rare.(2-4) Most common esophageal foreign body in neonates is a swallowed endotracheal tube, $(5,6)$ however, there are other examples mentioned in the literature including stone,(7) bean,(8) button ${ }^{(9)}$ and even a thumb tack.(10) Most of these cases were more than two weeks old. One of our patients had an endotracheal tube and another had a finger ring impacted in their esophagi, both were less than 72 hours old. 
If the incident has not been witnessed and the ingested object is radiolucent, the diagnosis of foreign body ingestion can be very tricky in neonates. Because respiratory distress is the most common manifestation of a foreign body in esophagus in younger children, it may lead to a misdiagnosis of some respiratory disorder. $(9,11)$ Beside typical symptoms of choking, gagging, dysphagia or drooling, esophageal foreign body in neonates has been associated with hematemesis and malena.(7) A simple x-ray followed by a contrast study (If needed) can help in establishing the diagnosis. The combined sensitivity and specificity of x-ray and contrast study is $99 \%$ and $80 \%$ respectively.(12) Fortunately in our cases the diagnosis was not much of a problem as one had a radioopaque foreign body (Finger ring) evident on x-ray with a typical presentation. The other baby had an evident event of ingesting a foreign body (Endotracheal tube).

Among children below 3 years of age the impaction of foreign body is common;(2) necessitating prompt removal. Frequent lodging sites are the constrictions at the levels of cricopharyngeus muscle, aorta, left main bronchus and lower esophageal sphincter. For removing a foreign body various methods have been described, like Foley's catheter, rigid endoscopy and fiber optic endoscopy.(13,14) While removal under direct vision is the method of choice, conventional pediatric esophagoscopes of small size are difficult to work with, because of limited "straw" vision.

This visual field is further diminished by the passage of manipulating instruments through the lumen. As a result, grasping takes place in a semi-blind manner. We found that this problem was overcome to a great extent by using an optical forceps within a small pediatric bronchoscopic channel. Its application combines the advantage of excellent visualization and a larger forceps, which can be applied with more precision. Swallowed or inhaled foreign bodies are among the most serious and common causes of morbidity and mortality in pre-school children. However, such occurrence is very rare in infants and newborns. With the introduction of the optical forceps in pediatric bronchoscope, it allows foreign body manipulation with excellent positional control of the tip in smaller diameter of neonatal esophagus. In our experience, we found it to be more convenient and efficient as compared to the conventional esophagoscope.

\section{REFERENCES:}

1. Al-Salem AH, Qaisarrudin S, Murugan A, et al. Swallowed foreign bodies in children: aspect of management. Ann Saudi Med 1995; 5: 419-21.

2. Elli PDM, ARdn GM. Esophageal foreign bodies in an infant. J Laryngol Otol 1973; 87: 691-8.

3. Crysdale WS, Sendi K.S, Yoo J. Oesophageal foreign bodies in children: 15 years review of 485 cases. Ann Otol Rhinol Laryngol 1991; 100: 320-24.

4. Jones NS, Lanningan FJ, Salama NY. Foreign bodies in the throat: a prospective study of 388 cases. J Laryngol Otol 1991; 105: 104 -8.

5. Banerjee A, Rao BK. Lower esophageal foreign body in a neonate (letter). Indian Pediatr 1983; 20: 384.

6. MacKinlay GA, Wilson Storey D, Hendry GM. The ectopic endotracheal tube. J R Coll Surg Edinburg 1987; 32: 310.

7. Thapa B R, Kaur B, Nagi B, et al. Unusual foreign body (stone) in the esophagus of a neonate mimicking tracheoesophageal fistula. Indian Pediatr 1993; 30: 943-5.

8. Dogruyol H, Gurpinar AN. A foreign body in a four-day-old infant's esophagus: a case of negligence. Turk J Pediatr 1989; 31: 163-6. 


\section{CASE REPORT}

9. Chowdhury CR, Bricknell MCM, MacIver D. Oesophageal foreign body: an unusual cause of respiratory symptoms in a three-week-old baby. J. Laryngol Otol 1992; 106: 556-7.

10. Al-Odaidan N, Amu OD, Fahmy M, et al. An unusual case of impacted esophageal foreign body. Saudi Med J 2000; 21: 202-3.

11. Friedman EM. Foreign bodies in the pediatric aero-digestive tract. Pediatr Ann 1988; 17: 640-2.

12. Taylor RB. Esophageal foreign bodies. Emergency medicine clinics of North Am 1987; 5: 30111.

13. Carlson DH. Removal of coins in the esophagus by using Foley's catheter. Pediatrics 1972; 50: 475.

14. Christie DL, Ament ME. Removal of foreign bodies from esophagus and stomach with flexible panendoscope. Pediatrics 1976; 57: 931-4.

\section{AUTHORS: \\ 1. Faiz muqtadir \\ 2. M. Muniraju \\ 3. Khalid Gufran}

\section{PARTICULARS OF CONTRIBUTORS:}

1. Senior Resident, Department of ENT, ESIC Medical College.

2. Professor, Department of ENT, DR BRAMCH.

FINANCIAL OR OTHER COMPETING INTERESTS: None
3. Lecturer, Department of periodontics, Salman Bin Abdul Aziz University, Al Kharj, KSA.

\section{NAME ADDRESS EMAIL ID OF THE} CORRESPONDING AUTHOR:

Faiz Muqtadir, H- No. 5-408/106/10, Islamabad Colony, Gulbarga.

E-mail:drfaiz.muqtadir@gmail.com

Date of Submission: 05/02/2015. Date of Peer Review: 06/02/2015. Date of Acceptance: 23/02/2015. Date of Publishing: 05/03/2015. 